\title{
Studies on Financial Quality Evaluation of Listed Steel Companies Based on DEA in China
}

\author{
Kai-Yang ZHANG \\ School of business administration \\ Jimei University \\ Xiamen, Fujian, 361021,P.R.C.
}

\author{
Hong LEI* \\ School of business administration \\ Jimei University \\ Xiamen, Fujian, 361021,P.R.C. \\ *Corresponding author
}

\begin{abstract}
In this paper, the DEA method is used to construct an enterprise financial quality evaluation model, and evaluate the financial quality of 23 listed steel companies in China. The quality will be analyzed and calculated from three aspects, comprehensive efficiency, technical efficiency and scale efficiency. The empirical results show that the financial quality of China's steel listed companies is not very good. The comprehensive efficiency of some steel listed companies is not as effective as DEA and the degree of impact on scale efficiency is greater than the technical efficiency. The company's production scale has not reached its optimal state. Also, according to the empirical results, some countermeasures and suggestions will be put forward to improve efficiency.
\end{abstract}

\section{Keywords—Listed Steel Companies, Financial Quality, DEA}

\section{INTRODUCTION}

The steel industry is the pillar industry of the national economy. It has a great influence on related industries such as construction, real estate, automobile, energy, home appliances, machinery manufacturing, etc. It plays an irreplaceable role in the industrial development of the country and the development of the national economy. An important indicator of a country's comprehensive development strength. In recent years, China's steel market has been sluggish and overcapacity has occurred. Most steel companies have experienced a decline in profits or even losses. Facing the severe market, iron and steel enterprises must improve their financial quality and enhance their competitiveness. In this paper, the financial quality of listed steel companies is taken as the research object to measure the quality of enterprise assets and earnings, risk and growth, providing decision-making reference for corporate management and external investors.

\section{LITERATURE REVIEW}

At present, the main evaluation methods for enterprise financial quality include wall scoring method, fuzzy comprehensive evaluation method, efficacy coefficient method, factor analysis method, analytic hierarchy processed. Wang Jianhua and Yang Suqin ${ }^{[1]}$ used the Woer weight scoring method to make a preliminary evaluation of the overall financial quality of 29 domestic listed companies in Henan Province; Liang Ying and $\mathrm{Xu} \mathrm{Na}{ }^{[2]}$ used fuzzy comprehensive evaluation of the comprehensive financial ability of listed companies; Wang Cuichun ${ }^{[3]}$ used the efficiency coefficient method to comprehensively evaluate the financial quality of agricultural listed companies; Tao Wei ${ }^{[4]}$ used a factor analysis method to study the financial quality evaluation of real estate listed companies; Lin Yanyun ${ }^{[5]}$ used a hierarchical analysis to evaluate the financial quality of listed companies.

The research on financial quality of iron and steel industry mainly focuses on financial risk, performance evaluation and capital structure. Liu Huahui studied the financial risks of 37 listed steel companies from 2007 to 2009 ${ }^{[6]}$. Gou Mengyong and Hou Xian conducted a comprehensive evaluation of the financial performance of China's central and western listed steel companies ${ }^{[7]}$. Based on the financial data of listed steel companies from 2004 to 2013, Pang Weihong, Li Kai and Li Gang studied the influence of capital structure on the market competitiveness of enterprises ${ }^{[8]}$. These studies provide strong theoretical support for the development of the industry, but there is relatively few literature on the financial quality evaluation of the steel industry. This paper uses DEA to evaluate the financial quality of listed steel companies, and analyzes the financial quality status of steel companies.

\section{The SeLECTION OF DEA MODEL}

Data envelopment analysis (DEA) is an evaluation method of the relative efficiency of decision-making unit in the condition of multi-input and multi-output. The financial quality evaluation index of this paper is the ratio relationship between the consumption and income of listed steel companies in financial activities, which essentially reflects the relationship between input and output. Therefore, it is feasible to use DEA method for research. Since the evaluation of financial quality belongs to the category of variable scale reward, this paper uses the BCC model to measure and analyze the financial quality of listed steel companies.

Suppose there are $\mathrm{n}$ evaluation units called decision units (DMUs), each of which has $\mathrm{m}$ kinds of input variables and $\mathrm{s}$ kinds of output variables, $\mathrm{X}_{i j}\left(\mathrm{X}_{i j}>0, \mathrm{i}=1,2, \ldots, \mathrm{m}\right)$ stands for the input quantity of $\mathrm{i}$-th input in the jth evaluation unit. $\mathrm{yrj}_{\mathrm{rj}}\left(\mathrm{y}_{\mathrm{rj}}>0, \mathrm{r}=1,2, \ldots, \mathrm{s}\right)$ indicates the output quantity of the $r$-th output of the $j$-th evaluation unit. Then, the input variable of the $j$-th evaluation unit can be recorded as $X_{j}=\left(X_{1 j}, X_{2 j}, \ldots, X_{m j}\right)^{T}$. The output variable, which can be recorded as $Y_{j}=\left(y_{1 j}, y_{2 j}, \ldots, y_{s j}\right)^{T}(j=1,2 \ldots, n)$, 
introduces the slack variable $S^{-}$and the residual variable $S^{+}$, and obtain the CCR model and the BBC model of DEA as follows: (and the output variable can be recorded as ... Meanwhile, the slack variable $S^{-}$and the residual variable $S^{+}$introduced to obtain the CCR model and the BBC model of DEA as follows:)

The CCR model:

$$
\begin{aligned}
& \min \boldsymbol{\theta}=\left[\boldsymbol{\theta}-\varepsilon\left(e^{T} \boldsymbol{S}^{-}+e^{T} \boldsymbol{S}^{+}\right)\right] \\
& \text {s.t. } \sum_{j=1}^{n} x_{j} \lambda j+s_{j}^{-}=\boldsymbol{O x}_{\mathrm{O}} \\
& \sum_{j=1}^{n} y_{j} \lambda-s^{+}=y 0
\end{aligned}
$$

BBC model: $\mathrm{J}=1,2, \ldots, \mathrm{n}$. ;

$\min \boldsymbol{\theta}=\left[\boldsymbol{\theta}-\varepsilon\left(\ell^{T} S^{-}+\ell^{T} S^{+}\right)\right]$

s.t. $\sum_{j=1}^{n} x_{j} \lambda_{j}+S^{-}=\theta_{X 0}$

$\sum_{j=1}^{n} y_{j} \lambda_{j}-S^{+}=y \mathrm{o}$

$\sum_{j=1}^{n} \lambda j=1$

$\lambda j \geq 0 ; j=1,2, \ldots, n ; S^{+}=0 ; S^{-}=0 ; \theta \in E^{1}$

Where, $\varepsilon$ is the non-archimedes infinite small quantity, $\lambda$ is the coefficient of the linear combination of decision-making units, $\theta$ is the effective value, and $S^{-}, S^{+}$respectively represents the relaxation variables of input and output.

When $\theta=1, s^{+}=S^{-}=0$, then DMU is strongly effective; When $\theta=1, S^{+} \neq 0$ and $S^{-}=0$, there is insufficient output, indicating that the output of some products can be increased under the condition of keeping the same input. When $\theta=1, S^{+}=0, S^{-} \neq 0$, there is a waste of resources, so part of the input can be reduced and the original output keeps unchanged; When $\boldsymbol{\theta}<1$, the decision-making units are completely ineffective.

\section{DATA AND VARIABLES}

\section{A. Index Selection}

According to the principles of scientific, comparability, representativeness, systematic, operability and other indicators system construction, combined with the characteristics of the steel industry, the total assets $\left(X_{1}\right)$, operating $\operatorname{cost}\left(X_{2}\right)$, sales cost $\left(X_{3}\right)$, management cost $\left(X_{4}\right)$ and financial cost $\left(X_{5}\right)$ are selected as input variables, and operating income $\left(Y_{1}\right)$ as the output variable.

In the input indicator, the total assets refer to all the assets that a company owns or can control to bring economic benefits; the operating cost is the input of operating income, which is considered from the internal management financial efficiency of the company; period costs including sales expenses, management fees and financial expenses are also important indicators that affect the financial quality of enterprises. The reason why the output indicator selects operating income is mainly because a listed company with great development potential must have a clear main business as the pillar. The statistical description of input-output variables is shown in TABLE I.

TABLE I. INPUT-OUTPUT VARIABLE STATISTICAL DESCRIPTION(UNIT: 100 MILLION YUAN)

\begin{tabular}{|c|c|c|c|c|c|}
\hline & Variable & Min & Max & Mean & Standard deviation \\
\hline \multirow{4}{*}{ Input } & $\mathrm{X} 1$ & 43.44 & 3351.41 & 711.96 & 754.79 \\
\cline { 2 - 6 } & $\mathrm{X} 2$ & 40.77 & 2590.85 & 517.85 & 52.02 \\
\cline { 2 - 6 } & $\mathrm{X} 3$ & 0.45 & 34.93 & 10.03 & 9.62 \\
\cline { 2 - 6 } & $\mathrm{X} 4$ & 1.63 & 129.57 & 18.78 & 26.94 \\
\cline { 2 - 6 } & $\mathrm{X} 5$ & 0.17 & 44.22 & 11.64 & 12.27 \\
\hline Output & $\mathrm{Y} 1$ & 47.94 & 3047.80 & 610.83 & 611.22 \\
\hline
\end{tabular}

\section{B. Data Sources output variable.}

The data in this paper is from the Guotaian Economic and Financial Research Database. According to the 2012 industry classification criteria of the CSRC, the data sample is the financial statement data published by the 2018 annual reports of Shanghai and Shenzhen listed steel companies. After the secondary screening, ST companies and incomplete data are excluded, and all input and output indexes cannot be negative as the DEA method requires. Also, experimental studies have shown that the negative treatment will affect the DEA results, making its distortion, and it will make the results of the analysis false in the process of mapping data. Therefore, samples with negative data such as Daye special steel, Shagang steel, Hangzhou steel, Fangda special steel and Wujin stainless steel are excluded in this paper. Finally, 23 listed steel companies were selected as research samples. The number of samples (23) is more than twice that of the product of inputoutput indexes (10), so it is considered that DEA evaluation results have an effective degree of differentiation.

\section{V.EMPIRICAL RESULTS AND ANALYSIS}

\section{A. Calculation Process and Result Analysis}

By combining sample data with DEA's BCC evaluation model and using DEAP2.1 software for analysis, the financial quality evaluation results of 23 listed steel companies in 2018 can be obtained, as shown in TABLE II.

TABLE II. FINANCIAL QUALITY AND EFFICIENCY OF LISTED STEEL COMPANIES IN 2018

\begin{tabular}{|c|c|c|c|c|}
\hline $\begin{array}{c}\text { Stock } \\
\text { Name }\end{array}$ & $\begin{array}{c}\text { Comprehensive } \\
\text { Efficiency }\end{array}$ & $\begin{array}{c}\text { Technical } \\
\text { Efficiency }\end{array}$ & $\begin{array}{c}\text { Scale } \\
\text { Efficiency }\end{array}$ & $\begin{array}{c}\text { Scale } \\
\text { returns }\end{array}$ \\
\hline Hegang steel shares & 1.000 & 1.000 & 1.000 & - \\
\hline Songshan steel & 0.532 & 0.546 & 0.973 & irs \\
\hline $\begin{array}{c}\text { Bengang } \\
\text { steel plate }\end{array}$ & 0.691 & 0.715 & 0.966 & irs \\
\hline Taigang stainless & 0.698 & 0.707 & 0.988 & drs \\
\hline Angang steel & 0.717 & 0.720 & 0.996 & drs \\
\hline $\begin{array}{c}\text { Valin iron } \\
\text { and steel }\end{array}$ & 0.565 & 0.570 & 0.990 & drs \\
\hline Shougang shares & 1.000 & 1.000 & 1.000 & - \\
\hline Three steel fujian light & 1.000 & 1.000 & 1.000 & - \\
\hline Yongxing special steel & 1.000 & 1.000 & 1.000 & - \\
\hline $\begin{array}{c}\text { Baotou steel } \\
\text { corporation }\end{array}$ & 1.000 & 1.000 & 1.000 & - \\
\hline $\begin{array}{c}\text { Bao steel } \\
\text { Shandong iron and } \\
\text { steel }\end{array}$ & 0.788 & 1.000 & 0.788 & drs \\
\hline
\end{tabular}




\begin{tabular}{|c|c|c|c|c|}
\hline \multicolumn{5}{|c|}{ Cont. to TABLE II } \\
\hline $\begin{array}{c}\text { Xining } \\
\text { special steel }\end{array}$ & 1.000 & 1.000 & 1.000 & - \\
\hline Lingang steel & 0.871 & 1.000 & 0.871 & irs \\
\hline Nangang & 0.822 & 0.831 & 0.99 & drs \\
\hline Ordos & 0.945 & 0.976 & 0.968 & drs \\
\hline Jiugang Hongxing & 0.537 & 0.544 & 0.986 & irs \\
\hline Anyang steel & 0.704 & 0.728 & 0.967 & irs \\
\hline $\begin{array}{c}\text { Bayi iron } \\
\text { and steel }\end{array}$ & 1.000 & 1.000 & 1.000 & - \\
\hline New steel shares & 1.000 & 1.000 & 1.000 & - \\
\hline Ma steel & 0.727 & 0.738 & 0.985 & irs \\
\hline Liugang & 1.000 & 1.000 & 1.000 & - \\
\hline $\begin{array}{c}\text { Chongqing iron and } \\
\text { steel }\end{array}$ & 1.000 & 1.000 & 1.000 & - \\
\hline Average value & 0.852 & 0.873 & 0.977 & \\
\hline
\end{tabular}

\section{B. The Analysis of Comprehensive Results}

The comprehensive efficiency value In table I appears that there are 11 listed steel companies that are DEA effective, and their technical efficiency and scale efficiency are both 1 , indicating that the financial resources of these 11 listed steel companies can be effectively allocated and utilized in 2018, and their financial quality is at a high level. The remaining 12 listed steel companies have not achieved DEA efficiency, which indicates that the financial quality of the 12 listed steel companies is relatively poor, with input redundancy or insufficient output.

According to the technical efficiency value analysis, there are 13 listed steel companies that are effective, indicating that in 2018, these companies paid more attention to the innovation and utilization of technology. The remaining 10 were invalid state, namely steel Songshan, Bengang steel plate, Taigang stainless, Angang steel, Valin iron and steel, Nangang, Ordos, Jiugang Hongxing, Anyang iron and steel shares and Ma steel shares. The above-mentioned listed company's financial quality did not achieve the best holistic coordination. The phenomenon of input redundancy and output deficiency existed and the financial quality was poor. The investment in research and development and the innovation ability need to be improved to enhance the technical efficiency of enterprises, so as to improve the quality of corporate finance.

From the analysis of the value of scale efficiency, there are 11 listed steel companies with effective scale efficiency and have reached the optimal scale, indicating that the financial resources of these companies have achieved the optimal allocation. The remaining 12 companies are in the state of increasing or decreasing scale. If the decision-making unit returns increases incrementally, it indicates that the company needs to expand the scale. To some extent, the larger the scale, the lower the production cost and the better the output effect. Table 1 shows that there are 6 listed steel companies (Songshan steel, Benshan steel, Lingang steel, Jiujiang hongxing steel, Anyang steel, Ma steel) with increasing returns on scale, and these companies need to expand the production scale and spread out the cost. If the size of the decision-making unit returns diminishes, it indicates that the company needs to reduce the size. There are 6 listed steel companies (Taigang stainless steel, Angang iron \& steel, Valin iron \& steel, Bao steel, Nangang iron \& steel, Ordos) with diminishing returns on scale. These companies should shift their development direction, adjust their product structure, focus on products with greater returns, and improve the utilization rate of existing resources.

Based on the above analysis, it can be found that the number of listed steel companies with effective technical efficiency in 2018 is 13. In 2018, the number of companies with an efficient scale is 11 . The number of listed steel companies with efficient technology is generally higher than that of companies with efficient scale. In 2018, the average comprehensive efficiency, technical efficiency and scale efficiency of China's listed steel companies are 0.852, 0.873 and 0.977 respectively. The average scale efficiency is higher than the average technical efficiency, indicating that the financial quality of listed steel companies is more affected by scale efficiency than technical efficiency. Therefore, the main reason for the poor financial quality level of listed steel companies is the low scale efficiency. In addition, the inputoutput unreasonable resource allocation caused by technical efficiency is also an important factor affecting the company's financial quality.

\section{CONCLUSIONS AND SUGGESTIONS}

The article uses the DEA method to evaluate the financial quality of 23 listed steel companies, and the conclusion shows that the overall financial quality level of 11 listed companies, namely the Hegang steel shares, Shougang shares, Three steel fujian light, Yongxing special steel, Baotou steel corporation, Shandong iron and steel, Xining special steel, Bayi iron and steel, New steel shares, Liugang, and Chongqing iron \& steel group co., is higher, and these companies have reached the DEA optimal state; The other 12 listed steel companies are DEA invalid. Among them, Bao steel and Lingang are invalid mainly because of scale reward, and the other 10 invalid enterprises are caused by the combination of scale reward and technical efficiency.

For listed iron and steel companies with effective financial comprehensive efficiency, their technical efficiency and scale return are in an ideal state. In order to ensure the existing financial input structure, we should continue to steadily increase financial input and promote the continuous, stable and efficient development of the company's financial operation.

For the listed steel companies of invalid type, there is redundancy in investment. The reasons for redundancy should be further analyzed and countermeasures should be found out. With the full use of existing technology and equipment, the input-output ratio and the quality of output need to be improved, the investment in research and development should be increased and the innovation ability ought to be enhanced, in order to achieve sustained and rapid development momentum, achieve economies of scale, improve the labor productivity and economic effect, raise profitability, and enhance the quality of the company's financial level.

\section{ACKNOWLEDGMENT}

This research was financially supported by the Foundation for Social Sciences research of Xiamen, No. XMSK2019C13. 


\section{REFERENCES}

[1]. Wang Jianhua, Yang Suqin. Financial quality evaluation of listed companies-- a case study of Henan province[J].Finance and accounting communications,2009(20):111-112. (In Chinese)

[2]. Liang Ying, Xu Na. Financial analysis based on fuzzy comprehensive evaluation -- a case study of two major steel companies in northwest China [J]. Finance and accounting communications,2019(02):88-91. (In Chinese)

[3]. Wang Cuichun, Wang Xin. Comprehensive evaluation of financial quality of agricultural listed companies based on efficiency coefficient method [J]. Economic and management review,2008,24(2):126-129. (In Chinese)

[4]. Tao Yi. Research on comprehensive evaluation of financial quality of listed real estate companies in China [D]. Xihua University,2017. (In Chinese)
[5]. Lin Yanyun. Financial quality evaluation of listed companies based on analytic hierarchy process [J]. China management informatization,2008(11):40-42. (In Chinese)

[6]. Lliu Huahui. Empirical study on financial risks of listed steel companies in China [J], friends of accounting, 2010(12):84-87. (In Chinese)

[7]. Meng Yong, Hou Xian. Research on financial performance evaluation of listed steel companies in central and western China [J]. Journal of north China university (social science edition),2014,30(04):56-61. (In Chinese)

[8]. Pang Weihong, Li Kai, Li Gang. Influence of capital structure on market competitiveness of enterprises--based on panel data of listed companies in steel industry [J]. Journal of finance and accounting,2015(32):21-23. (In Chinese) 